\title{
ON SOME PECULIARITIES OF ETHYL 5-HYDROXY-1,2-DIMETHYL-1H-3-INDOLECARBOXYLATE SYNTHESIS
}

\author{
Felix Shepel, Diana Shepel, Fliur Macaev* \\ Institute of Chemistry of the Academy of Sciences of the Republic of Moldova, \\ Academy str. 3, MD-2028, Chisinau, Republic of Moldova \\ Tel+373-22-739-754; Fax+373-22-739-954; E-mail: flmacaev@cc.acad.md
}

\begin{abstract}
The increase of yield up to $63 \%$ of ethyl 5-hydroxy-1,2-dimethyl-1H-3-indolecarboxylate was obtained via the interaction of $p$-benzoquinone with $\mathrm{N}$-methyl- $\beta$-aminocrotone ether in mixture of glacial acetic acid/ethyl acetate.
\end{abstract}

Keywords: derivatives of 5-oxindole, cardio-vascular remedies.

\section{Introduction}

Many physiologically active compounds with a wide spectrum of activities have been found among indole derivatives [1-5]. A representative of this series - preparation "Dimecarbine" - ethyl 5-hydroxy-1,2-dimethyl-1H-3indolecarboxylate has been suggested for treatment of cardio-vascular diseases [6,7].

\section{Results and discussion}

It is well known that the chemical reaction forming 5-hydroxyindole derivatives from benzoquinone and $\beta$ aminocrotonic esters represents the classical Nenitzescu indole synthesis [8-10].

The synthesis of ethyl 5-hydroxy-1,2-dimethyl-1H-3-indolecarboxylate 3 consists of the cycle formation reaction between 1,4-benzoquinone 2 and ester $\mathbf{1}$ in acetone or 1,2-dichloroethane.<smiles>CCOC(=O)/C=C(/C)NC</smiles>

1<smiles>O=C1C=CC(=O)C=C1</smiles>

2<smiles>CCOC(=O)c1c(C)[nH]c2ccc(O)cc12</smiles>

$3 \mathrm{Me}$

However, both reported methods gave only up to $18 \%$ of targeted compound 3. Such a low yield of the product can, probably, be explained by the instability of benzoquinone due to oxidation, which results in the breaking of the cycle or the polymer formation. Moreover, the spontaneous transformation of quinone into hydroquinone, which, in turn forms with quinone the colored quinhydrone, may influence upon the yield of the final product.

On the other side, it is known the initial interaction of the acetic acid with $\beta$-aminocrotonic esters and $p$ benzoquinones leads to the suppression of side reaction [10].

With the optimized conditions in our hands, the scope of the reaction was examined with variety of solvents. Finally, it was find that the replacement 1,2-dichloroethane or acetone by solution of the acetic acid in ethyl acetate leads to the augmentation of the yield of compound 3 up to $63 \%$. It is worth noting that, it is possible to isolate 3 after a single recrystallization of the formed precipitate (look experimental part).

\section{Conclusion}

In summary, we have described a reaction of $p$-benzoquinone with $\mathrm{N}$-methyl- $\beta$-aminocrotone ether in mixture of glacial acetic acid/ethyl acetate. This method represents a simplicity approach for preparing and isolation of the ethyl 5-hydroxy-1,2-dimethyl-1H-3-indolecarboxylate.

\section{Experimental methods}

All the used solvents were of reagent quality, and all commercial reagents were used without additional purification. Removal of all solvents was carried out under reduced pressure. Analytical TLC plates were Silufol ${ }^{\circledR}$ UV-254 (Silpearl on aluminium foil, Czecho-Slovakia). IR spectra were recorded on a Spectrum 100 FT-IR spectrophotometer (Perkin -Elmer) using the universal ATR sampling accessory. ${ }^{1} \mathrm{H}$ and ${ }^{13} \mathrm{C}$ NMR spectra have been recorded for $\left(\mathrm{CD}_{3}\right)_{2} \mathrm{SO} 2-\%$ solution on a "Bruker -Avance III" (400.13 and 100.61 MHz).

Ethyl N-methyl- $\beta$-aminocrotonate 1 has been prepared according to the known procedure [7].

Preparation of ethyl 5-hydroxy-1,2-dimethyl-1H-3-indolecarboxylate 3. The mixture of $\mathbf{1}$ (7.9 g, 0.055 $\mathrm{mol})$ and acetic acid $(3.2 \mathrm{ml}, 0.053 \mathrm{~mol})$ in ethyl acetate $(30 \mathrm{ml})$ were added to a solution of $5 \mathrm{~g}(0.046 \mathrm{~mol}) \mathrm{of} 2 \mathrm{and}$ 
glacial acetic acid $(2.7 \mathrm{ml}, 0.044 \mathrm{~mol})$ in ethyl acetate $(35 \mathrm{ml})$ so that the temperature in the reaction mass does not exceed $30^{\circ} \mathrm{C}$ (use ice/water bath). The residue was stirred for 1 hour, followed by distillation of the solvent $(20 \mathrm{ml})$ and storing in the refrigerator for 24 hours at $0-10^{\circ} \mathrm{C}$. The formed precipitate is separated, washed on filter by means of cold ethyl acetate. In result $7.2 \mathrm{~g}$ of solid substance with m.p. $180-190^{\circ} \mathrm{C}$ is obtained. After recrystallization from ethyl acetate $6.79 \mathrm{~g}$ of 3 were obtained. The yield was $63 \%$. M.p. $215-216^{\circ} \mathrm{C}$. Lit. [7]. M.p. $210-215^{0} \mathrm{C}$. IR $\left(\mathrm{v} / \mathrm{cm}^{-1}\right)$ : $3274(\mathrm{OH}), 2991,2941,1445,1375\left(\mathrm{Me}, \mathrm{CH}_{2}\right), 2791(\mathrm{~N}-\mathrm{Me}), 1751(\mathrm{C}=\mathrm{O}), 1637,1622,1595,1521,1479,1019$, 870, 835, 803, 764, 668 (indole), 1333, 1212, 1288, 1093 (C-O). Spectrum NMR ${ }^{1} \mathrm{H}(\delta, \mathrm{ppm}, J / \mathrm{Hz}): 1.35, \mathrm{t}(3 \mathrm{H},-$ $\left.\mathrm{CH}_{2} \mathrm{Me}, J=4\right), 2.68 \mathrm{~s}(3 \mathrm{H}, \mathrm{Me}-\mathrm{C}=), 3.64 \mathrm{~s}(3 \mathrm{H}, \mathrm{N}-\mathrm{Me}), 4.28, \mathrm{q}\left(2 \mathrm{H},-\mathrm{CH}_{2} \mathrm{Me}, J=4\right), 6.67,6.68 \mathrm{~d}, \mathrm{~d}\left(1 \mathrm{H},{ }^{6} \mathrm{CH}\right.$, $\left.J_{4,6}=2.4, J_{6,7}=8.4\right), 7.25 \mathrm{~d}\left(1 \mathrm{H},{ }^{7} \mathrm{CH}, J=8.8\right), 8.47 \mathrm{~d}\left(1 \mathrm{H},{ }^{4} \mathrm{CH}, J_{4,6}=2.4\right), 8.95 \mathrm{~s}(1 \mathrm{H}, \mathrm{OH})$. Spectrum NMR ${ }^{13} \mathrm{C}(\delta$, ppm): $165.60\left(\mathrm{CO}_{2}\right), 153.10\left({ }^{5} \mathrm{C}\right), 145.67\left({ }^{2} \mathrm{C}\right), 131.14\left({ }^{7 \mathrm{a}} \mathrm{C}\right), 127.56\left({ }^{3 \mathrm{a}} \mathrm{C}\right), 111.72\left({ }^{6} \mathrm{C}\right), 110.69\left({ }^{7} \mathrm{C}\right), 105.95\left({ }^{4} \mathrm{C}\right)$, $102.37\left({ }^{3} \mathrm{C}\right), 59.06\left(\mathrm{CH}_{2}\right), 29.98(\mathrm{NMe}), 14.97\left({ }^{2} \mathrm{CMe}\right), 12.08\left(\mathrm{CH}_{2} \mathrm{Me}\right)$. Mol. For. $\mathrm{C}_{13} \mathrm{H}_{15} \mathrm{NO}_{3}$. Cal. C 66.94; H 6.48; N 6.0. Find C 67.3; H 6.13; N 6.28 .

\section{References}

[1]. Macaev, F. Synthesis of spiroindolin-2-ones from $1 H$-indole-2,3-dione. In "Selected methods for synthesis and modification of heterocycles". Vol. 3. The chemistry of synthetic indole systems. IBS press, 2004, pp 75-102.

[2]. Landwehr, J.; George, S.; Karg, E. M.; Poeckel, D.; Steinhilber, D.; Troschuetz, R.; Werz O. J. Med. Chem. 2006, 49, 4327-4332.

[3]. Srivastava, S. S.K.; Husbands, S.M.; Lewis J.W. J. Med. Chem. 2005, 48, 635-638.

[4]. Bohme, T.M.; Augelli-Szafran, C.E.; Hallak, H.; Pugsley, T.; Serpa, K.; Schwarz, R.D. J. Med. Chem. 2002, 45, 3094-3102.

[5]. Swann, E.; Barraja, P.; Oberlander, A.M.; Gardipee, W.T.; Hudnott, A.R.; Beall, H.D.; Moody, C.J. J. Med. Chem. 2001, 44, 3311-3319.

[6]. Mashcovskii, M.D.; Medicinal remedies. Chişinău: Cartea Moldovenească, 1990, 1, 391.

[7]. Rubtsov, M.V.; Baichikov, A.G. Synthetical pharmaceutical preparates; Medicine, Moscow, 1971, 158-159.

[8]. Nenitzescu, C.D. Chemical Society Bulletin Romania 1929, 11, 37. Chem. Zbl. 1929, 2, S.2331.

[9]. Gil, C.; Brase S. Journal of Combinatorial Chemistry, 2009, 11, 175-197.

[10]. Ronn, M.; McCubbin, Q.; Winter, S.; Veige, M.K.; Grimster, N.; Alorati, T.; Plamondon L. Organic Process Research \& Development. 2007, 11, 241-245. 